\title{
Psychomotor development of preterm babies in the context of biomedical predictors in a Polish sample
}

\begin{abstract}
BACKGROUND
Preterm birth represents the most frequent complication of pregnancy all over the world. Much research is addressed to psychomotor development of preterm infants during the initial years of their life. Many authors emphasize the role of birth weight, gestational age, and gender in determining the child's psychomotor development. This study adds to this knowledge as we analyzed the synergistic effect of biomedical predictors such as gestational age, birth weight, Apgar score, time in incubator, type of pregnancy defined based on its outcome, neonatal status immediately after delivery, infant's gender, and possessing twin sibling. Combined effects of these factors represent an important niche in the studies of the developmental psychology of preterm infants.
\end{abstract}

\section{PARTICIPANTS AND PROCEDURE}

The study included 49 preterm infants born in 2008-2009 at the Department of Obstetrics of the Medical University of Gdańsk. The psychomotor development of preterm infants was evaluated according to the Bayley Scales of Infant and Toddler Development ${ }^{\circledR}$, Third Edition (BSID-III) at a mean, non-corrected age of 33.80 months $(S D=5.16)$. For the purpose of the study we developed a basic model in the form of a pathway diagram, describing the cumulative influence of eight biomedical predictors on the development of the infants during early childhood.

\section{RESULTS}

Our study revealed a synergistic influence of biomedical predictors on the development of preterm infants with regards to cognitive functioning ( $28 \%$ of variance), language skills ( $10 \%$ of variance), motor skills ( $18 \%$ of variance), fine motor skills ( $16 \%$ of variance), and gross motor skills ( $20 \%$ of variance). Moreover, we observed an independent effect of birth weight, child's gender, and final Apgar score on the psychomotor development of preterm infants. Higher birth weight was associated with higher level of cognitive function and fine motor skills. Male gender of a child was reflected by a higher level of cognitive function and language skills, including expressive communication. Finally, higher final Apgar scores resulted in better gross motor skills.

\section{CONCLUSIONS}

This study confirmed the independent influence of biomedical predictors, such as birth weight, gender, and Apgar score, on the psychomotor development of preterm babies during early childhood. Medical factors play a crucial role in the evaluation of psychomotor development in preterm infants, and their importance should not be undervalued.

\section{KEY WORDS}

psychomotor development; preterm infants; early childhood; biomedical predictors; BSID-III

organizations - 1: Institute of Psychology, University of Gdansk, Poland · 2: GAMUT, Uni Health, Uni Research, Bergen, Norway

AUthors' CONTRibution - A: Study design - B: Data collection - C: Statistical analysis - D: Data interpretation .

E: Manuscript preparation · F: Literature search · G: Funds collection

CORRESPONDING AUtHOR - Prof. Mariola Bidzan, Institute of Psychology, University of Gdansk, 4 Bażyńskiego Str., 80-952 Gdansk, Poland, e-mail: mariola.bidzan@ug.edu.pl

to Cite this ARTicle - Bidzan, M. \& Bieleninik, Ł. (2013). Psychomotor development of preterm babies in the context

of biomedical predictors in a Polish sample. Health Psychology Report, 1, 18-33. DOI: 10.5114/hpr.2013.40466 


\section{BACKGROUND}

As preterm birth is a final deliverable of a multifactorial process, it is sometimes referred to as preterm parturition syndrome (Gotsh et al., 2009). Currently, preterm birth represents the most frequent complication of pregnancy. The lowest preterm birth rates (3-6\%) were documented in Scandinavian countries, the Netherlands, and France, and the highest (above $30 \%$ ) in India and Philippines. The preterm birth rate in Europe is around 5-7\% and in the United States $8-11 \%$. The prevalence of preterm births in Poland decreases gradually every year but still is higher than in other developed European countries, ranging between $4.5 \%$ and $12 \%$ (Czajka, 2010; Bieleninik, 2012; Bidzan, Bieleninik \& Lipowska, 2013).

Prematurity is not only the most frequent cause of perinatal mortality but can also be associated with persistent health problems during the neonatal and infantile period, or even in subsequent life, resulting from the immaturity of vital organs of a newborn. Anatomical and functional differences between preterm neonates and full-term newborns pertain to all vital organs. Respiratory problems of preterm newborns and immaturity of their lungs constitute one of the most significant clinical problems as they can be associated with mortality risk. It is widely postulated that respiratory problems in preterm neonates result from quantitative and qualitative abnormalities of alveolar surfactant. The respiratory failure of preterm neonates can also be associated with immaturity of the respiratory tract (including lower content of collagen and elastin in pulmonary tissue and pulmonary vessels), fragile structure of the chest, and the deficiency of neurotransmitters controlling the normal breathing rate. Respiratory pathologies that can be observed in preterm infants include respiratory distress syndrome (RDS), bronchopulmonary dysplasia (BPD), inborn pneumonia, and apnea. Also the thermogenesis is impaired in preterm neonates, due to their lower content of brown adipose tissue, small reserve of glycogen, decreased muscle tone, significant thermal loss through the skin, and a tendency to adopt the external temperature; therefore, preterm neonates should be kept in incubators. Moreover, they show an array of alimentary disorders. Due to the lack or poorly developed sucking reflex, as well as the lack of swallowing and coughing reflexes, preterm newborns have difficulties with food ingestion. Therefore, neonates with LBW frequently require enteral or parenteral nutrition. Necrotizing enterocolitis is the most frequent gastrointestinal problem in preterm babies. The list of cardiovascular abnormalities of preterm neonates includes persistent pulmonary hypertension of the newborn, and patent ductus arteriosus (PDA). Moreover, preterm newborns show an array of immaturity-related disorders of the nervous system. This refers especially to muscle tone, the cerebral respiratory center that is responsible for so-called motor drive, and the presence of reflexes which are specific for preterm neonates and the intrauterine environment. Immaturity of the brain in preterm infants is also manifested by a different spectrum of neurological complications than in full-term newborns, resulting from differences in morphology and localization of changes in the central nervous system (CNS). Noticeably, as many as $95 \%$ of injuries of the CNS occur during the fetal and neonatal period. The most frequent abnormalities observed in preterm infants include bleeding (intraventricular, periventricular, or subarachnoid hemorrhage), leukomalacia, and infections. Other unique anatomical characteristics of newborns delivered before gestational week 37 pertain to the skin and immune system. It is the immature skin barrier which is frequently the cause of infections, as well as the reason for thermoregulatory and water-electrolyte disorders. The endocrine disorders of preterm newborns refer mostly to carbonate and calcium metabolism, and the thyroid gland. Additionally, preterm neonates show abnormalities of the hematopoietic system, urinary tract, and skeletal system. Furthermore, termination of pregnancy before gestational week 37 can also be reflected by abnormal vision and hearing of a neonate. Aside from retinopathy of prematurity (ROP), preterm neonates are more frequently affected by strabismus (4- to 5-fold higher risk), myopia (approximately three times more frequent than in full-term babies), nystagmus, bilateral disorders of vision, lack of visual acuity, and cataract of prematurity (Kostuch, 2009).

Noticeably, the group of premature babies comprises both neonates delivered at the $6^{\text {th }}$ month of pregnancy and those born at gestational month 9. This is reflected by variable clinical status, anthropometric parameters, and requirements for perinatal care. This fact has significant prognostic value. Children delivered preterm are at risk of neurodevelopmental disorders (Martens et al., 2003; Woodward et al., 2006), especially cerebral palsy and mental impairment (e.g. Martens et al., 2003; van Kessel-Feddema et al., 2007; Wechsler Linden, Paroli \& Doron, 2007; Bidzan \& Bieleninik, 2013). A number of studies have addressed the psychomotor development of preterm babies during initial years of their life. Premature infants constitute a risk group of various developmental disorders, deficits, and disharmonies, as well as delayed development and/or impairment (e.g. Saigal et al., 2003; Ragusa, 2009; Wielenga et al., 2009). It is of note that the premature population also includes babies which do not differ from their peers delivered after gestational week 37 in terms of psychomotor development; this refers mostly to children born between the $34^{\text {th }}$ and $36^{\text {th }}$ week of pregnancy, i.e. so-called late preterm infants. However, there are also neonates with ELBW and young gestational age, who constitute a particu-
Psychomotor development of preterm babies 
Descriptive characteristics of newborns extracted from their medical and nursing documentation

\begin{tabular}{crrrr}
\hline Perinatal parameters & \multicolumn{1}{c}{ M } & SD & Min & Max \\
\hline Gestational age & 33.33 & 2.82 & 26 & 36 \\
Birth weight & 1952.45 & 715.72 & 550 & 3870 \\
Birth length & 44.63 & 5.65 & 31 & 60 \\
Head circumference & 31.14 & 4.29 & 23 & 49 \\
Chest circumference & 27.50 & 3.72 & 18 & 34 \\
\hline
\end{tabular}

Mariola Bidzan, Łucja Bieleninik

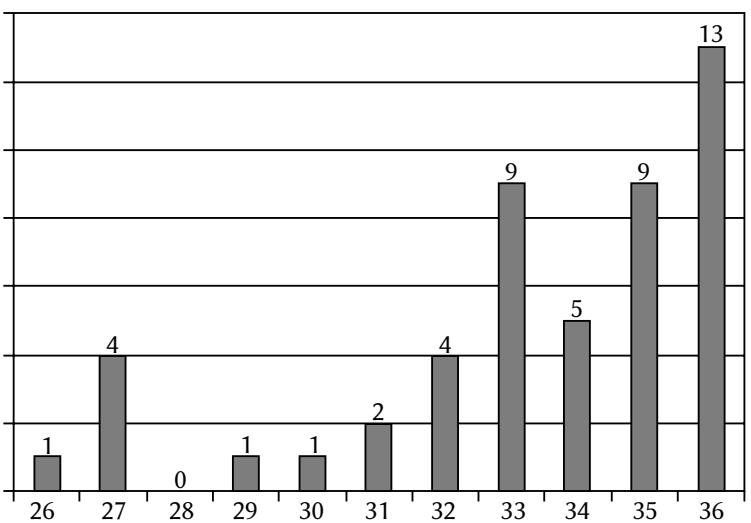

Figure 1. Histogram presenting the distribution of gestational age.

lar risk group of impaired psychomotor development (Bracewell \& Marlow, 2002). Due to advances in neonatology, also newborns delivered at the $23^{\text {rd }}$ week of pregnancy (e.g. Wechsler Linden et al., 2007; Field, Dorling, Manktelow \& Draper, 2008), or even those born at gestational week 22, can be saved (Rijken et al., 2003). These so-called fetal infants have the highest risk of perinatal mortality and neurodevelopmental complications.

As the normal psychomotor development of a child is determined by the course of pregnancy and delivery, adaptation to the intrauterine environment, and perinatal complications, the prevention of developmental abnormalities should include the analysis of obstetrical and neonatal variables.

The aim of the research was to assess psychomotor development of preterm babies in the context of biomedical predictors.

\section{PARTICIPANTS AND PROCEDURE}

The study was a part of a research project completed in cooperation between the Department of Obstetrics of the Medical University of Gdańsk and the Institute of Psychology of the University of Gdańsk. The project consisted of two stages. The first stage took place in 2007-2008 and included analysis of medical and nursing documentation. The second stage took place between 2010 and 2011, and included the determi- nation of the psychomotor development of children according to the Bayley Scales of Infant and Toddler Development ${ }^{\circledast}$, Third Edition (BSID-III) scale and the American reference levels. Additionally, the project constituted an attempt to normalize BSID-III for the Polish population.

The study included 49 preterm infants born in 20082009 at the Department of Obstetrics of the Medical University of Gdańsk. The study group included 21 single babies (42.86\%) and 28 twins (57.14\%); these figures did not correspond to the number of pregnancies. Taking into account the number of fetuses, 34 infants (69.39\%) originated from twin pregnancies, and 15 (30.61\%) from singleton pregnancies. This discrepancy resulted from the fact that among twin pregnancies there were 11 pregnancies complicated by twin-to-twin transfusion syndrome (TTTS), and in six of them only one live newborn was delivered. The analysis of medical and nursing documentation revealed that 8 infants $(16.32 \%)$ were born by natural routes, and $41(83.65 \%)$ by cesarean section. Taking into account the presentation at delivery, 31 newborns (70.89\%) resumed normal cephalic presentation, 6 (13.34\%) breech presentation, and 7 (15.77\%) transverse presentation.

Descriptive statistics of preterm newborns extracted from their medical and nursing documentation are summarized in Table 1.

Mean gestational age of preterm newborns was 33.33 weeks $(S D=2.82$, range $26-36$ weeks $)$. The distribution of gestational age in the study group is presented in Figure 1.

It is of note that 9 newborns (18.37\%) were delivered before gestational week 32 , and $4(8.16 \%)$ in the $32^{\text {nd }}$ week of pregnancy. Gestational age of the majority of babies exceeded 32 weeks, including 9 newborns born in the $33^{\text {rd }}$ or $35^{\text {th }}$ week $(18.37 \%$ each), $5(10.20 \%)$ in the $34^{\text {th }}$ week, and $13(26.53 \%)$ in the $36^{\text {th }}$ week. Late preterm infants represented more than half of the study group ( $n=27,55.10 \%)$.

Mean birth weight of studied newborns was $1952.45 \mathrm{~g}(S D=715.72$; range 550-3870 g). One newborn was delivered with incredibly low birth weight (ILBW) amounting to $550 \mathrm{~g}, 4(8.16 \%)$ with extremely low birth weight (ELBW), $10(20.40 \%)$ with very low birth weight (VLBW), 24 (49\%) with low birth weight 
(LBW), and 10 babies (20.40\%) were born with birth weight exceeding $2500 \mathrm{~g}$. The distribution of birth weight in the study group is presented in Figure 2.

We did not observe any final Apgar score below 5 points, although 5 newborns $(10.20 \%)$ scored 4 at the first measurement. Moreover, 4 (8.16\%) and 2 babies $(4.08 \%)$ scored 5 points at the first and final measurement, respectively. The number of newborns who scored 10 points at the $1^{\text {st }}$ minute and at the final measurement was $4(8.16 \%)$ and $7(14.29 \%)$, respectively. Most of the newborns scored $7(n=13,26.53 \%)$ or 8 points $(n=11,22.45 \%)$ at the first measurement, and 8 points $(n=20,40.82 \%)$ at the final measurement. The distribution of Apgar scores at the $1^{\text {st }}$ minute and at the final measurement is presented in Figure 3.

Additionally, the status of babies immediately after delivery was examined by a neonatologist. The study group included 40 newborns $(81.63 \%)$ delivered in a good status, 7 (14.29\%) with signs of hypoxia, and $2(4.08 \%)$ born with asphyxia. The variability with regards to gestational age, birth weight, and Apgar scores determined further postnatal differences, especially with regards to adaptation to the extrauterine environment. The analysis of medical documentation revealed that 40 babies $(81.63 \%)$ were placed in an incubator. Mean time in an incubator was 15.17 days, and the maximal incubator stay was 120 days. Half of the babies (50\%) required oxygen therapy. Eighteen newborns (45\%) were diagnosed with RDS, $2(5 \%)$ with pneumonia, $15(37.5 \%)$ with infection, 3 (7.5\%) with PDA, another $3(5 \%)$ with intraventricular hemorrhage, and periventricular hemorrhage was detected in one child (2.5\%). Retinopathy of prematurity was diagnosed in 9 babies $(22.5 \%)$, BPD in $4(10 \%)$, apnea in $2(5 \%)$, ischemia in $16(40 \%)$, hypoxia in $15(37.5 \%)$, hyperbilirubinemia in $19(47.5 \%)$, and hypoglycemia in $6(15 \%)$. Additionally, the post-TTTS status was documented in some cases. The postnatal status of a preterm neonate determines the way of its feeding; 9 neonates $(18.36 \%)$ were breastfed, 16 (32.65\%) formula-fed, and 24 (48.9\%) remained on mixed feeding.

During early childhood 4 babies $(8.16 \%)$ were diagnosed with disability, including cerebral palsy in two girls from multiple pregnancies and in another pair of twins. One boy suffered from multiple disability: impairment of hearing (treated with an implant) and cerebral palsy. One girl was diagnosed with Pierre-Robin syndrome and decreased muscle tone. Mean age of children at the evaluation of psychomotor development according to BSID-III was 33.80 months $(S D=5.16)$, and the result of bootstrap estimation corresponded to 34.12 months $(S D=5.21)$. Single infants and twins did not differ significantly in terms of age at the examination (Table 2).

To study the psychomotor development of preterm infants in the context of biomedical predictors we developed a basic model in the form of a pathway diagram, presented in Figure 4. We assumed that

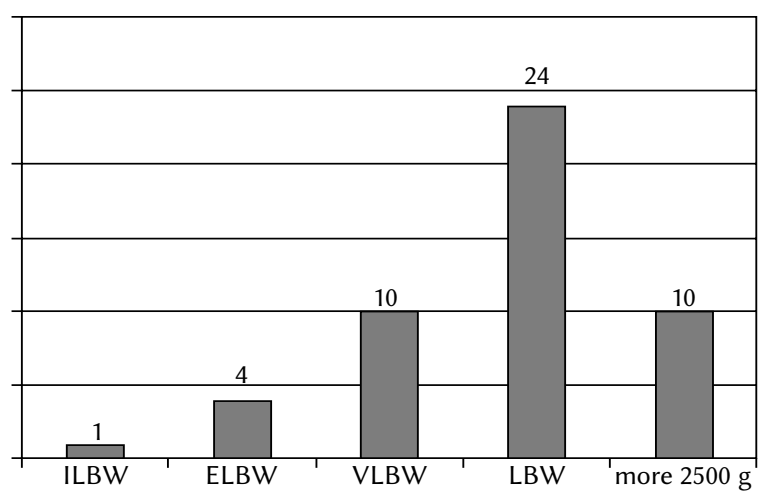

Figure 2. Histogram presenting the distribution of birth weight.

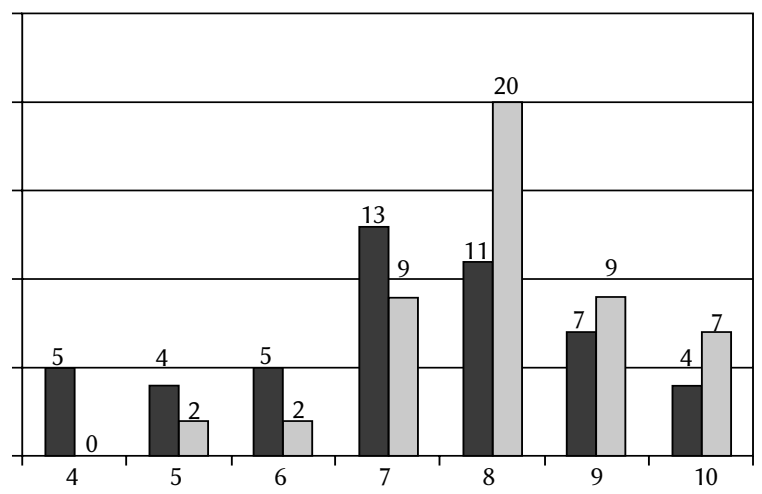

Figure 3. Histogram presenting the distribution of Apgar scores at the $1^{\text {st }}$ minute and at the final measurement.

8 predictors modulate various spheres of child development. Three of the studied predictors - type of pregnancy (normal vs. high-risk pregnancy), possessing a twin sibling (single infant vs. twin), and child's gender - were not correlated with the remaining predictors. The other five predictors - gestational age, postnatal status, birth weight, Apgar score, and time in incubator - were strongly correlated with each other, influencing the health status of a neonate. These correlations are depicted in the scheme as double-headed arrows. The predictors modulated various indices of BSID-III. This influence was estimated on the basis of a structural equation model with the generalized least square method and bootstrap-type estimation with 10000 repeats. The significance of the model parameters was estimated on the basis of $95 \%$ percentile range of the bootstrap estimator distribution.

\section{BIOMEDICAL PREDICTORS}

Our study included the following predictors:

- gestational age: mean 33.33 weeks, range 26-36 weeks;

- birth weight: mean 1952.45 g, range 559-3870 g;

- final Apgar score: 5-6 points $(n=2,4.08 \%), 7$ points $(n=9,18.37 \%), 8$ points $(n=20,40.82 \%), 9$ points $(n=9,18.37 \%), 10$ points $(n=7,14.29 \%)$;
Psychomotor development of preterm babies 
Table 2

Statistical characteristics of age at the evaluation of psychomotor development according to BSID-III

Mariola Bidzan, Łucja Bieleninik

\begin{tabular}{|c|c|c|c|c|c|c|c|c|c|c|c|c|c|c|c|}
\hline & & \multicolumn{3}{|c|}{ Single infants } & \multicolumn{3}{|c|}{ Twins } & \multirow[b]{2}{*}{$T$} & \multirow[b]{2}{*}{$d f$} & \multirow[b]{2}{*}{$P$} & \multirow{2}{*}{$\begin{array}{c}\text { Cohen } \\
D\end{array}$} & \multicolumn{4}{|c|}{$\begin{array}{c}\text { Bartlett test for } \\
\text { variance }\end{array}$} \\
\hline & & $M$ & $S D$ & $N$ & $M$ & $S D$ & $N$ & & & & & $F$ & $d f 1$ & $d f 2$ & $P$ \\
\hline \multicolumn{2}{|c|}{ Crude } & 32.86 & 4.15 & 21 & 34.51 & 5.77 & 28 & -1.159 & 47 & 0.126 & -0.34 & 1.936 & 28 & 21 & 0.061 \\
\hline Bootstrap & Estimator & 32.87 & 3.98 & 21 & 34.52 & 5.61 & 28 & -1.250 & 47 & 0.092 & -0.36 & 2.186 & 28 & 21 & 0.034 \\
\hline \multirow{2}{*}{$\begin{array}{c}95 \% \\
\text { confidence } \\
\text { interval }\end{array}$} & $\begin{array}{l}\text { Lower } \\
\text { limit }\end{array}$ & 31.05 & 2.72 & & 32.36 & 4.32 & & -0.987 & & 0.072 & -0.44 & 2.391 & & & 0.009 \\
\hline & $\begin{array}{l}\text { Upper } \\
\text { limit }\end{array}$ & 34.70 & 5.24 & & 36.68 & 6.90 & & -1.513 & & 0.112 & -0.29 & 1.980 & & & 0.059 \\
\hline
\end{tabular}

- time in incubator: 40 newborns $(81.63 \%)$ were placed in an incubator for a mean period of 15.17 days; the longest incubator stay was 120 days;

- type of pregnancy: 36 newborns $(73.47 \%)$ originated from high-risk pregnancies;

- status of newborn immediately after birth: good ( $n=40,81.63 \%)$, signs of hypoxia $(n=7,14.29 \%)$, asphyxia $(n=2,4.08 \%)$;

- child's gender: 29 girls and 20 boys;

- possessing twin sibling: 21 single infants (42.86\%), and 28 twins (57.14\%).

\section{RESULTS}

\section{COGNITIVE DEVELOPMENT OF PRETERM INFANTS IN CONTEXT OF BIOMEDICAL PREDICTORS}

Our analysis confirmed a significant effect of eight biomedical predictors of cognitive function $(\mathrm{Cog})$
$\left(R^{2}=0.285, p=0.002\right)$. We identified the two predictors which had the strongest impact on the skills from this sphere, i.e. birth weight $(\beta=0.575, p=0.022)$, and gen$\operatorname{der}(\beta=-0.258, p=0.058)$. Consequently, the higher the birth weight was, the higher were Cog scores and related skills in a given child. Moreover, the Cog scores were higher in boys. The data on the significance of regression coefficients for eight analyzed biomedical predictors in determining the Cog are presented in Table 3. Noticeably, the influence of analyzed predictors explained $28 \%$ of the variance (Figure 5).

\section{LANGUAGE DEVELOPMENT OF PRETERM INFANTS IN CONTEXT OF BIOMEDICAL PREDICTORS}

Our analysis confirmed the significant influence of eight studied biomedical predictors on language skills (Lang) $\left(R^{2}=0.100, p=0.022\right)$. On detailed analysis, male gender proved the only significant determinant

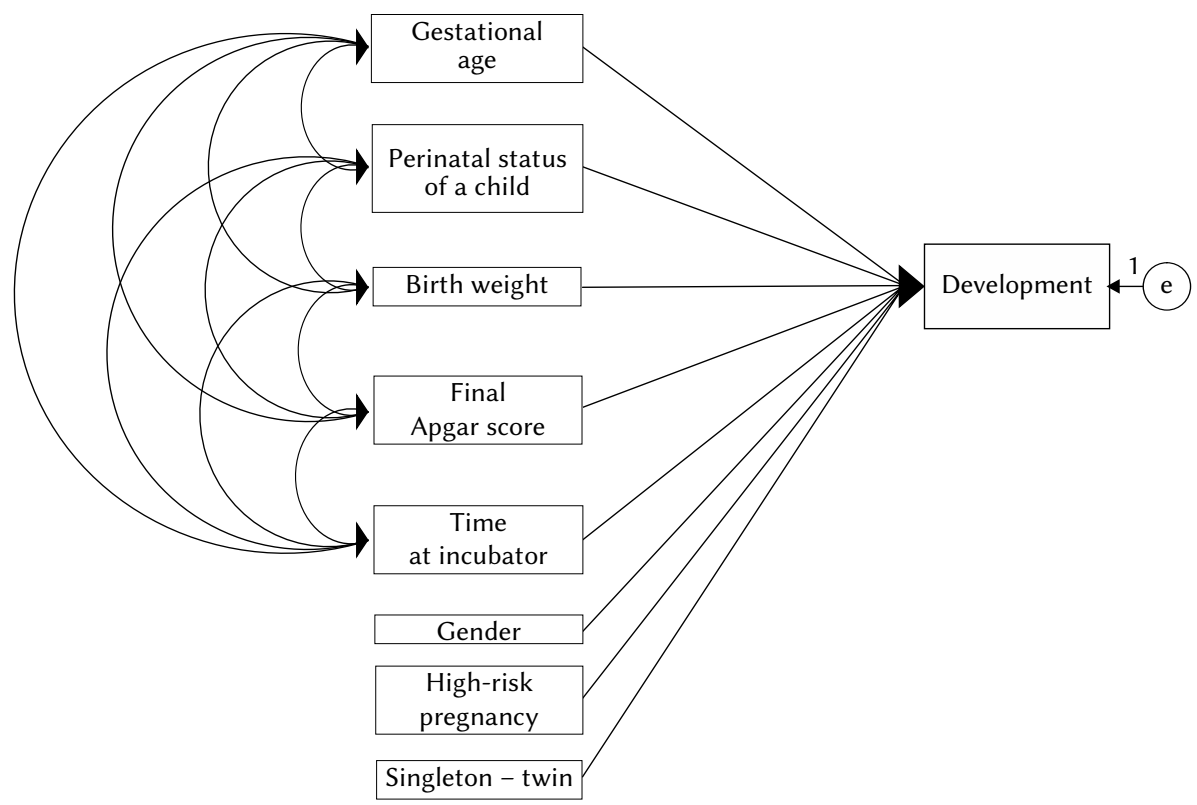

Figure 4. Model illustrating the influence of biomedical predictors on the psychomotor development of a child. 
Table 3

Significance of the standardized regression coefficients describing the influence of eight analyzed biomedical predictors on the Cog scores

\begin{tabular}{ccccc}
\hline Parameter & Value & \multicolumn{2}{c}{$95 \%$ confidences interval } & \multirow{2}{*}{ Significance } \\
\cline { 3 - 4 } & & Lower limit & Upper limit & \\
\hline Perinatal status of a child & 0.048 & -0.297 & 0.513 & 0.734 \\
Birth weight & 0.575 & 0.126 & 0.925 & $0.022^{*}$ \\
Final Apgar score & -0.142 & -0.476 & 0.288 & 0.435 \\
Time in incubator & 0.083 & -0.354 & 0.723 & 0.703 \\
Gender & -0.258 & -0.435 & 0.008 & $0.058^{\mathrm{A}}$ \\
Singleton - twin & 0.164 & -0.079 & 0.332 & 0.182 \\
Gestational age & -0.049 & -0.555 & 0.678 & 0.992 \\
High-risk pregnancy & -0.091 & -0.315 & 0.112 & 0.266 \\
$R^{2}$ & 0.285 & 0.202 & 0.641 & $0.002^{* *}$ \\
\hline
\end{tabular}

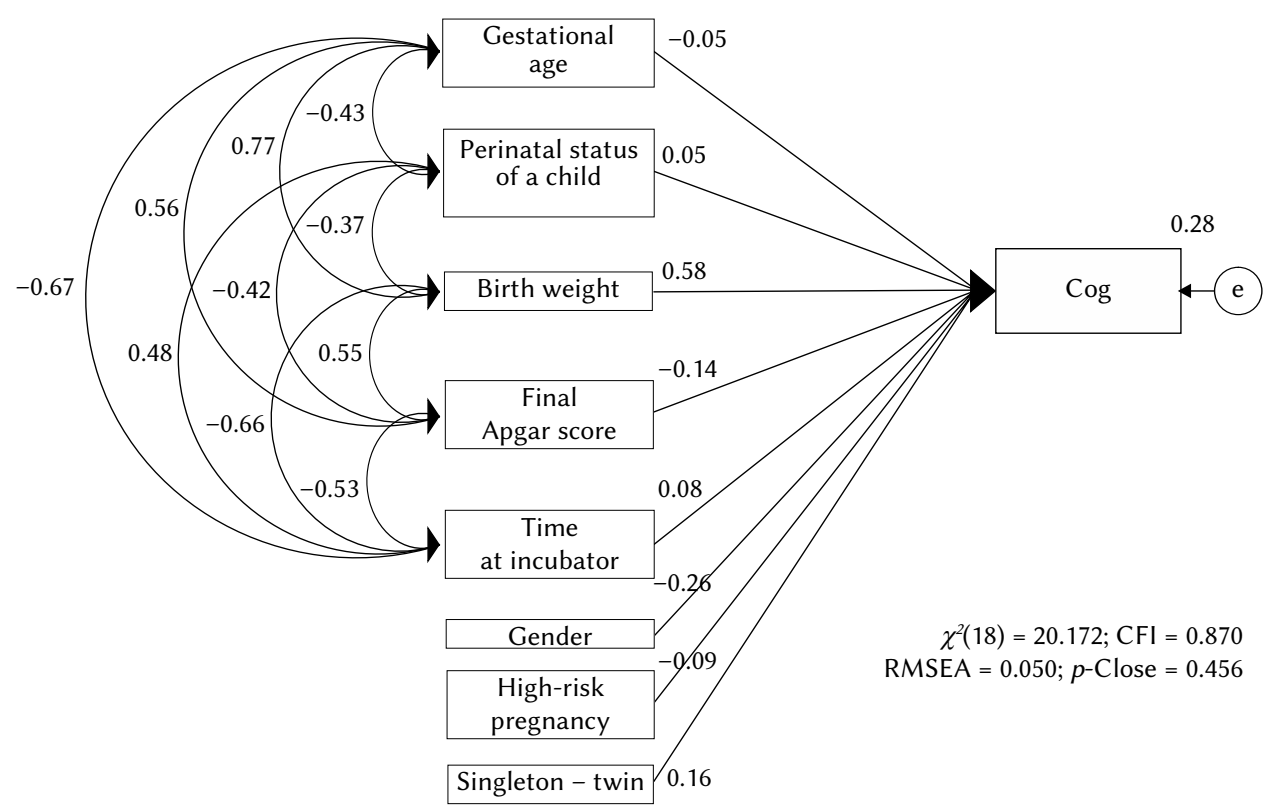

Figure 5. Model illustrating the influence of biomedical predictors on the Cog scores.

of this sphere $(\beta=-0.238, p=0.043)$. Consequently, boys scored significantly higher on the BSID-III scale of Lang, as shown in Table 4. The model illustrating the influence of biomedical predictors on the results of the Lang scale is presented in Figure 6.

Analyzing the influence of biomedical predictors on the development of Lang related to receptive communication (RC) and expressive communication (EC) we did not reveal any significant effect of gestational age, perinatal status, birth weight, final Apgar score, time in incubator, child's gender, or possessing a twin sibling in these spheres. These findings indicate the lack of significant cumulative influence of eight analyzed biomedical predictors on the RC $\left(R^{2}=0.157, p=0.102\right.$; Table 5 and Figure 7$)$ and EC scores $\left(R^{2}=0.157, p=0.102\right.$; Table 6 and Figure 8$)$. It is of note that the cumulative influence of eight analyzed biomedical predictors explained $16 \%$ and $15 \%$ of variance in $\mathrm{RC}$ and $\mathrm{EC}$, respectively.

\section{MOTOR DEVELOPMENT OF PRETERM INFANTS IN CONTEXT OF BIOMEDICAL PREDICTORS}

We observed a significant cumulative effect of eight analyzed biomedical predictors on the motor skills (Mot) of studied children $\left(R^{2}=0.181, p=0.010\right)$. The influence of the biomedical predictors explained $18 \%$ of variance in Mot. However, none of the biomedical predictors proved to be a significant determinant of the motor skills when analyzed separately. The data on the significance of regression coefficients
Psychomotor development of preterm babies 
Table 4

Significance of the standardized regression coefficients describing the influence of eight analyzed biomedical predictors on the Lang scores

Mariola Bidzan, Łucja Bieleninik

\begin{tabular}{ccccc}
\hline Parameter & Value & \multicolumn{2}{c}{$95 \%$ confidence interval } & \multirow{2}{*}{ Significance } \\
\cline { 3 - 4 } & & Lower limit & Upper limit & \\
\hline Perinatal status of a child & 0.032 & -0.036 & -0.368 & 0.255 \\
Birth weight & 0.109 & 0.036 & -0.5 & 0.546 \\
Final Apgar score & -0.189 & -0.06 & -0.477 & 0.296 \\
Time in incubator & -0.13 & 0.011 & -0.506 & 0.566 \\
Gender & -0.238 & -0.211 & -0.381 & $0.043^{*}$ \\
Singleton - twin & 0.083 & 0.029 & -0.257 & 0.222 \\
Gestational age & 0.184 & 0.218 & -0.361 & 0.849 \\
High-risk pregnancy & 0.041 & -0.056 & -0.346 & 0.174 \\
$R^{2}$ & 0.100 & 0.091 & 0.502 & 0.022 \\
\hline
\end{tabular}

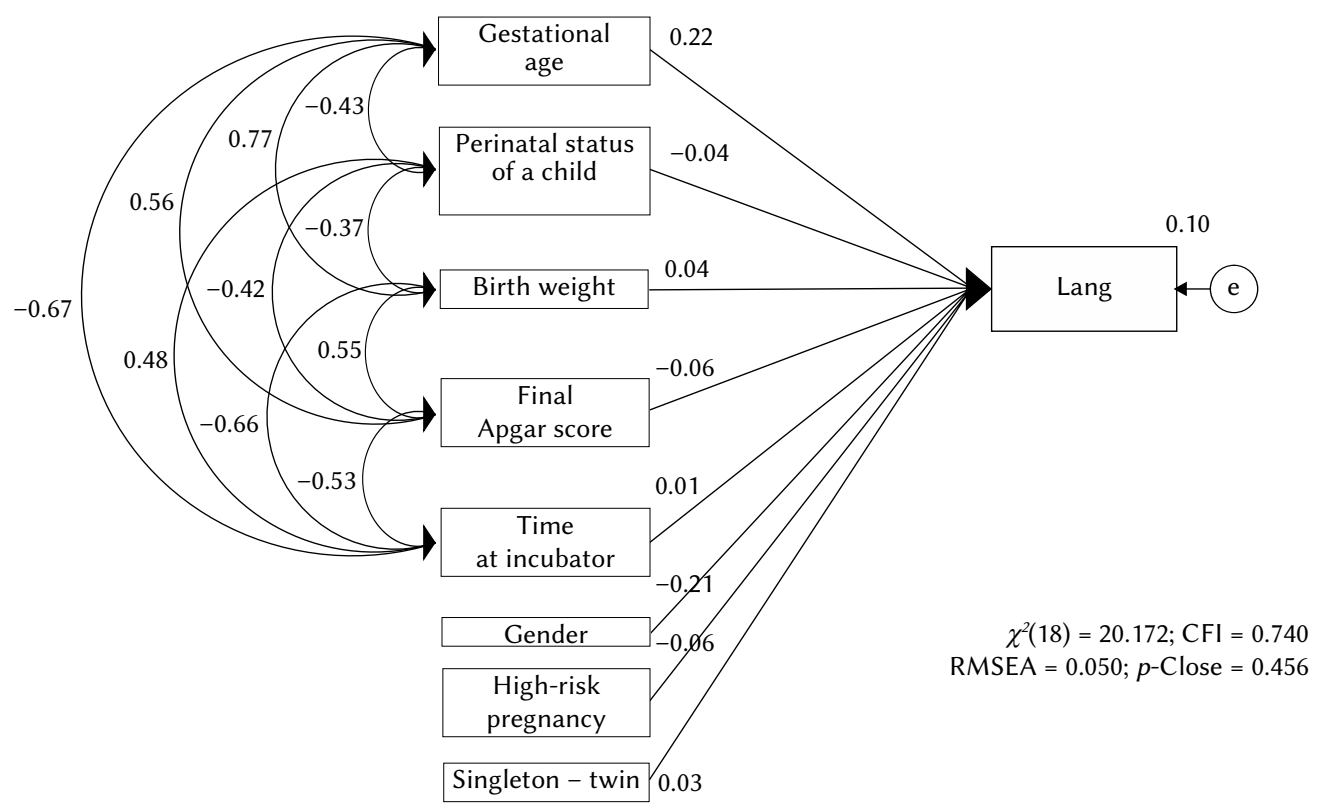

Figure 6. Model illustrating the influence of biomedical predictors on the Lang scores.

for eight analyzed biomedical predictors in determining the Mot are presented in Table 7 and in Figure 9.

Additionally, the cumulative effect of eight analyzed biomedical predictors proved to be a significant determinant of fine motor (FM) skills $\left(R^{2}=0.163\right.$, $p=0.012)$. Moreover, we identified two individual predictors which significantly influenced children's skills in this sphere: birth weight $(\beta=0.376, p=0.043)$ and final Apgar score $(\beta=-0.303, p=0.045)$. Consequently, children with higher birth weight and a lower Apgar score achieved significantly higher results on the FM scale. The influence of analyzed biomedical predictors explained $16 \%$ of variance in the FM skills. The data on the significance of regression coefficients for eight analyzed biomedical predictors in determining the FM scores are presented in Table 8 and in Figure 10.

Furthermore, the eight analyzed biomedical predictors exerted a significant cumulative effect on the gross motor (GM) skills $\left(R^{2}=0.203, p=0.002\right)$. Additionally, one of the predictors, final Apgar score, significantly influenced children's skills in this sphere on separate analysis $(\beta=0.317, p=0.079)$. Consequently, children with higher Apgar scores achieved higher scores on the GM scale during their early childhood. Cumulatively, the studied biomedical predictors explained $20 \%$ of variance in the GM skills. The data on the significance of regression coefficients for eight analyzed biomedical predictors in determining the GM scores are presented in Table 9 and in Figure 11. 
Table 5

Significance of the standardized regression coefficients describing the influence of eight analyzed biomedical predictors on the RC scores

\begin{tabular}{ccccc}
\hline Parameter & Value & \multicolumn{2}{c}{$95 \%$ confidence interval } & \multirow{2}{*}{ Significance } \\
\cline { 3 - 4 } & & Lower limit & Upper limit & 0.198 \\
Birth weight & -0.201 & -0.468 & 0.117 & 0.720 \\
Final Apgar score & 0.093 & -0.328 & 0.515 & 0.672 \\
Time in incubator & 0.134 & -0.307 & 0.477 & 0.176 \\
Gender & 0.312 & -0.124 & 0.792 & 0.805 \\
Singleton - twin & -0.042 & -0.213 & 0.166 & 0.407 \\
Gestational age & -0.088 & -0.389 & 0.136 & 0.514 \\
High-risk pregnancy & 0.19 & -0.42 & 0.849 & 0.132 \\
$R^{2}$ & -0.175 & -0.475 & 0.058 & 0.102 \\
\hline
\end{tabular}

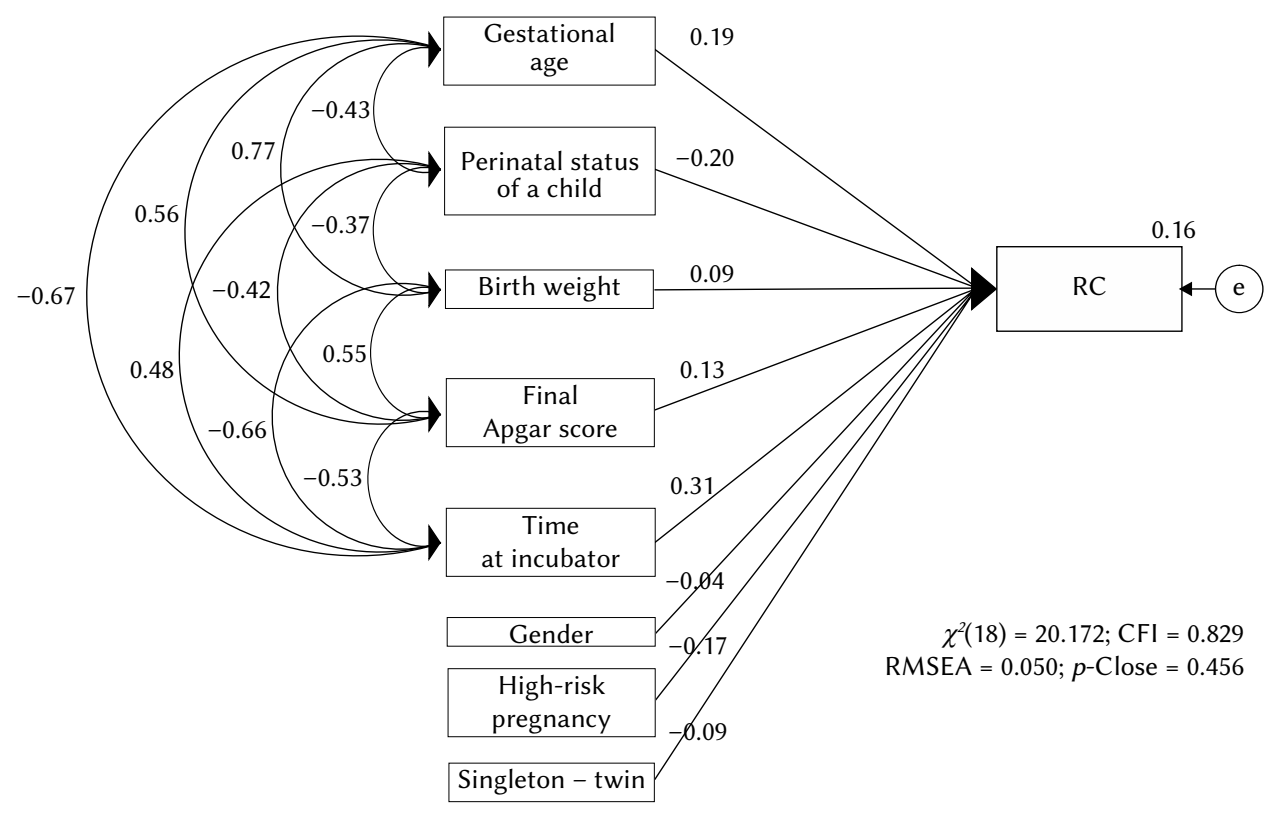

Figure 7. Model illustrating the influence of biomedical predictors on the RC scores.

\section{DISCUSSION}

A lot of previous studies dealing with the problem in question centered around the determinants of child development, including perinatal factors that were classified as biomedical predictors in our study. Many authors emphasize the role of birth weight, gestational age, and gender in determining psychomotor development during childhood. Our study adds to this knowledge as we analyzed the synergistic effect of biomedical predictors such as gestational age, birth weight, Apgar score, time in incubator, type of pregnancy defined based on its outcome, neonatal status immediately after delivery, baby's gender, and possessing a twin sibling. Combined effects of these factors represent an important niche in the studies of the developmental psychology of preterm infants. Due to their specificity associated with maturation of vital organs in the extrauterine environment, preterm infants differ markedly from their full-term peers. Undoubtedly, medical factors play a crucial role in the evaluation of psychomotor development in preterm infants, and their importance should not be undervalued. They not only determine the postnatal status of a child and its adaptation to extrauterine life, but also modulate the psychomotor development. Moreover, they mutually influence each other, e.g. birth weight is associated with gestational age, which in turn is reflected by postnatal status, which
Psychomotor development of preterm babies 
Table 6

Significance of the standardized regression coefficients describing the influence of eight analyzed biomedical predictors on the EC scores

Mariola Bidzan, Łucja Bieleninik

\begin{tabular}{ccccc}
\hline Parameter & Value & \multicolumn{2}{c}{$95 \%$ confidence interval } & \multirow{2}{*}{ Significance } \\
\cline { 3 - 4 } & & Lower limit & Upper limit & \\
\hline Perinatal status of a child & 0.032 & -0.352 & 0.333 & 0.737 \\
Birth weight & 0.109 & -0.367 & 0.525 & 0.656 \\
Final Apgar score & -0.189 & -0.567 & 0.142 & 0.253 \\
Time in incubator & -0.13 & -0.595 & 0.364 & 0.568 \\
Gender & -0.238 & -0.42 & 0.009 & $0.067^{\mathrm{A}}$ \\
Singleton - twin & 0.083 & -0.184 & 0.28 & 0.714 \\
Gestational age & 0.184 & -0.393 & 0.737 & 0.450 \\
High-risk pregnancy & 0.041 & -0.244 & 0.249 & 0.942 \\
$R^{2}$ & 0.152 & 0.009 & 0.521 & 0.102 \\
\hline
\end{tabular}

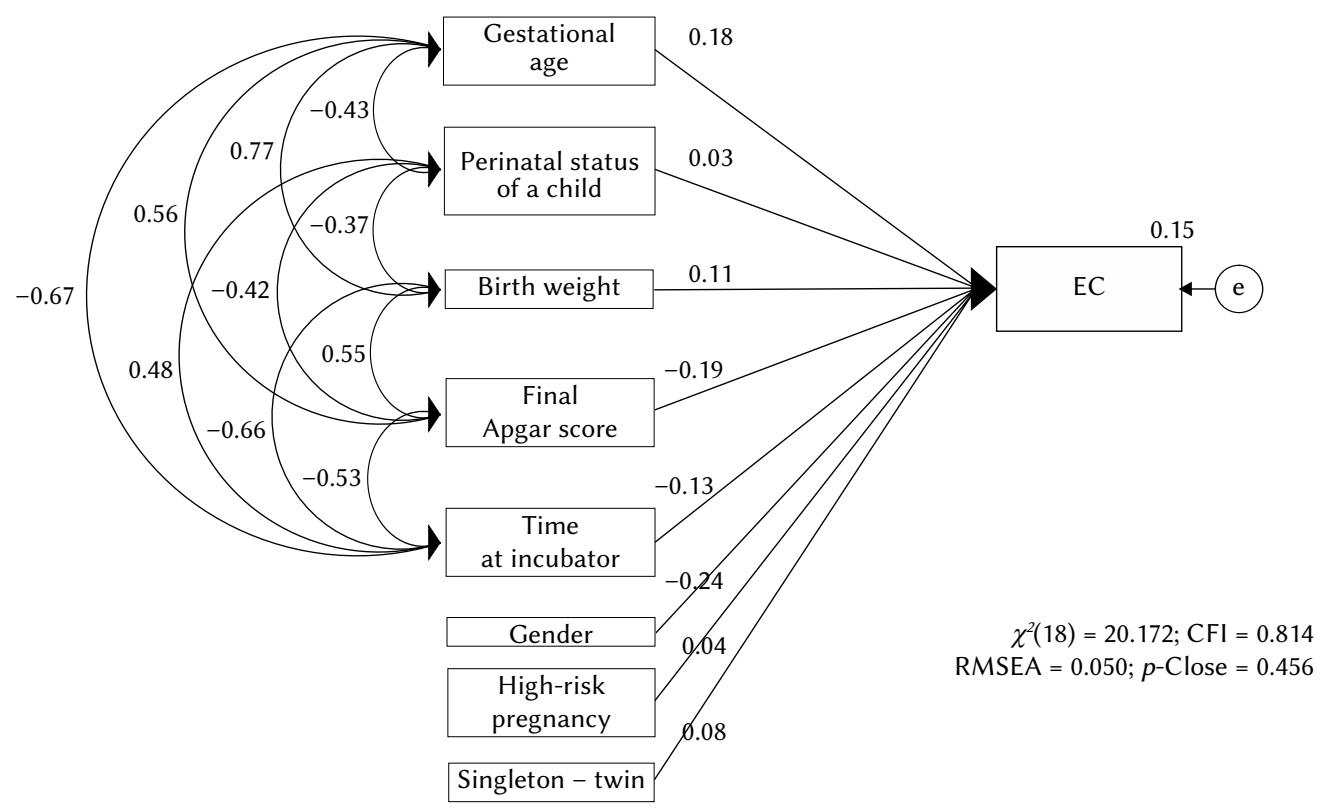

Figure 8. Model illustrating the influence of biomedical predictors on the EC scores.

decides upon the necessity of incubator stay and its duration. Our study revealed that biomedical predictors exert a synergistic effect on the early development of preterm babies with regards to cognitive functioning (whereby they explain $28 \%$ of variance), language skills ( $10 \%$ of variance), motor skills ( $18 \%$ of variance), as well as fine ( $16 \%$ of variance) and gross motor skills ( $20 \%$ of variance).

Our study confirmed the independent influence of biomedical predictors, such as birth weight, gender, and Apgar score, on the psychomotor development of preterm babies during early childhood. We observed that higher birth weight was associated with better cognitive functioning and fine motor skills. In turn, male gender of a child was reflected by better cogni- tive functioning and language skills, including expressive communication. Finally, a higher Apgar score determined better gross motor skills of preterm infants.

Both our findings and literature evidence confirm that child's gender is a predictor of their development (Morris et al., 2002; Stoelhorst et al., 2003; Wood et al., 2005; van Kessel-Feddema et al., 2007). However, we also revealed that male gender of a child is associated with better cognitive functioning and language skills, including expressive communication. Similar relationships have not been previously reported in literature dealing with the problem in question. For example, Wood et al. (2005) studied a group of 308 newborns from the UK and Ireland born at the $25^{\text {th }}$ week of intrauterine life and a smaller group of 30-month- 
Table 7

Significance of the standardized regression coefficients describing the influence of eight analyzed biomedical predictors on the Mot scores

\begin{tabular}{ccccc}
\hline Parameter & Value & \multicolumn{2}{c}{$95 \%$ confidence interval } & \multirow{2}{*}{ Significance } \\
\cline { 3 - 4 } & & Lower limit & Upper limit & 0.746 \\
Birth weight & 0.049 & -0.210 & 0.345 & 0.193 \\
Final Apgar score & 0.286 & -0.220 & 0.703 & 0.893 \\
Time in incubator & 0.005 & -0.292 & 0.400 & 0.261 \\
Gender & 0.306 & -0.233 & 0.696 & 0.539 \\
Singleton - twin & -0.096 & -0.341 & 0.158 & 0.480 \\
Gestational age & 0.091 & -0.137 & 0.319 & 0.298 \\
High-risk pregnancy & 0.287 & -0.313 & 0.650 & 0.320 \\
$R^{2}$ & -0.132 & -0.384 & 0.099 & 0.010 \\
\hline
\end{tabular}

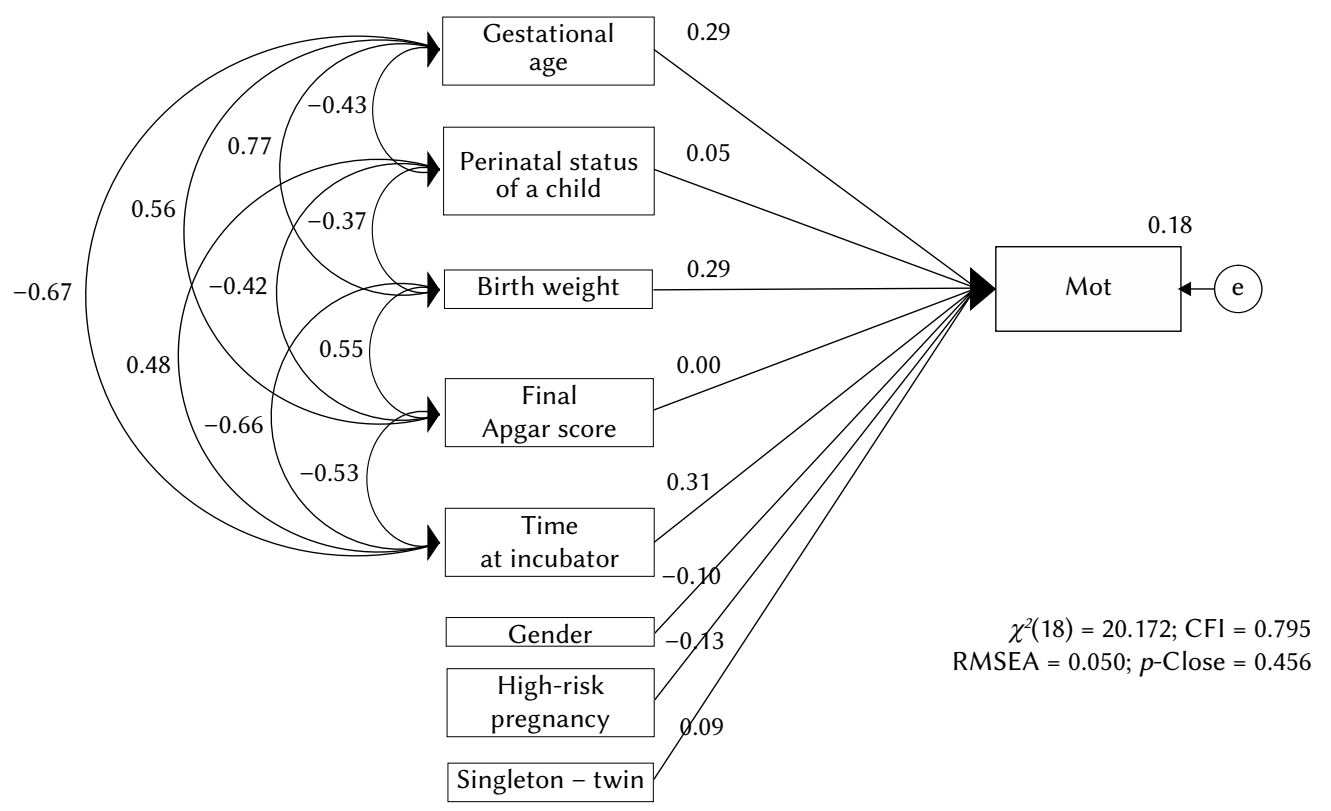

Figure 9. Model illustrating the influence of biomedical predictors on the Mot scores.

old infants, and observed that male gender constitutes a risk factor for lower motor scores, cerebral palsy, and motor impairment. Moreover, the risk of developmental disorders is modulated by unisexuality of children from multiple pregnancies (Kornacka, 2003).

Also gestational age constitutes a risk factor for neurological disorders and developmental delay (e.g. Wood et al., 2005; Woodward et al., 2006; Sondaar et al., 2008; Kiechl-Kohlendorfer et al., 2009; Maguire et al., 2009). Several studies have revealed that gestational age at preterm birth influences child's IQ at older age (Marlow, Wolke, Bracewell \& Samara, 2005; Mulder, Pitchford, Hagger \& Marlow, 2009). Moreover, gestational age seems to be the main factor determining the risk of generalized cogni- tive deficits in preterm infants (Mudler et al., 2009). Furthermore, often although not always boys rather than girls experience more severe consequences of low gestational age at birth (e.g. Marlow et al., 2005). A Swedish study conducted by Hemgren \& Persson (2004) analyzed the association between gestational age at birth (four groups: I - weeks 23-32; II - weeks 32-36; III - weeks 37-42; and IV - weeks 37-42) and the risk of delayed psychomotor development. The study revealed that at the age of three years, children with the lowest gestational age at birth (group I) show a higher level of motor dysfunction than preterm infants who were born at older gestational ages (group II) and healthy full-term neonates (group IV). According to Hack et al. (1999, after: Rijken et al.,
Psychomotor development of preterm babies 
Table 8

Significance of the standardized regression coefficients describing the influence of eight analyzed biomedical predictors on the FM scores

Mariola Bidzan, Łucja Bieleninik

\begin{tabular}{ccccc}
\hline Parameter & Value & \multicolumn{2}{c}{$95 \%$ confidence interval } & \multirow{2}{*}{ Significance } \\
\cline { 3 - 4 } & & Lower limit & Upper limit & \\
Perinatal status of a child & 0.036 & -0.227 & 0.341 & 0.849 \\
Birth weight & 0.376 & 0.009 & 0.724 & $0.043^{*}$ \\
Final Apgar score & -0.303 & -0.668 & -0.009 & $0.045^{*}$ \\
Time in incubator & -0.001 & -0.426 & 0.365 & 0.912 \\
Gender & -0.128 & -0.298 & 0.091 & 0.276 \\
Singleton - twin & 0.101 & -0.159 & 0.335 & 0.485 \\
Gestational age & 0.046 & -0.446 & 0.495 & 0.914 \\
High-risk pregnancy & -0.127 & -0.324 & 0.066 & 0.195 \\
$R^{2}$ & 0.163 & 0.078 & 0.540 & 0.012 \\
\hline
\end{tabular}

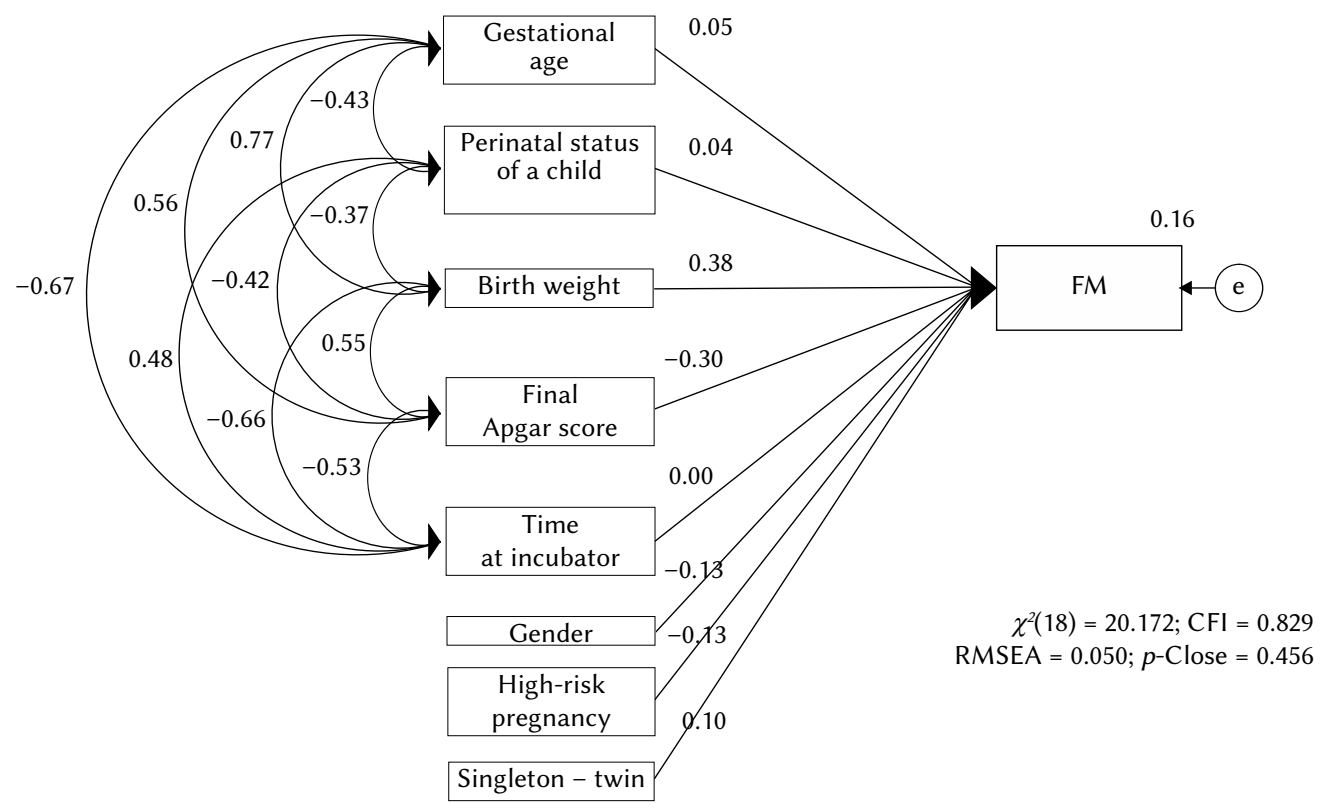

Figure 10. Model illustrating the influence of biomedical predictors on the FM scores.

2003), the scores of preterm infants are highly variable and depend on gestational age at birth. They highlighted that severe impairment occurs in 30\% of babies born at the $23^{\text {rd }}$ gestational week, $17 \%$ to $45 \%$ of neonates delivered at gestational week 24 , and in $12-35 \%$ of those with gestational age of 25 weeks. Another study (Hemgren \& Persson, 2006) revealed that babies born preterm at younger gestational ages (between the $23^{\text {rd }}$ and $31^{\text {st }}$ week) show delayed development in 2 out of 14 spheres analyzed with the Motor-Perceptual Development instrument, as compared to preterm neonates delivered at older age (gestational age between 32 and 36 weeks) and full-term newborns (gestational age 37-43 weeks); as many as $11 \%$ of the children showed various degrees of delay in the motor-perceptual scale along with evident deficits of coordination and attention. This suggests that the deficits of coordination and attention are associated with delayed development in the motor-perceptual sphere, considered vital for gaining skills required for everyday life and kindergarten education (Hemgren \& Persson, 2006). A Dutch study by Rijken et al. (2003) showed unfavorable outcomes (mortality, neurological disorders, impaired psychomotor development or delayed mental development) in $92 \%$ of children born between gestational weeks 23 and $24,64 \%$ of babies delivered at the $25^{\text {th }}$ week, and in $35 \%$ and $18 \%$ of those from the $26^{\text {th }}$ and $27^{\text {th }}$ week of pregnancy, respectively. Therefore, contrary to our findings, this study unambiguously confirmed 
Table 9

Significance of the standardized regression coefficients describing the influence of eight analyzed biomedical predictors on the GM scores

\begin{tabular}{ccccc}
\hline Parameter & Value & \multicolumn{2}{c}{$95 \%$ confidence interval } & \multirow{2}{*}{ Significance } \\
\cline { 3 - 4 } & & Lower limit & Upper limit & \\
\hline Perinatal status of a child & -0.003 & -0.275 & 0.284 & 0.920 \\
Birth weight & 0.068 & -0.304 & 0.597 & 0.698 \\
Final Apgar score & 0.317 & -0.037 & 0.747 & $0.079^{\mathrm{A}}$ \\
Time in incubator & 0.123 & -0.176 & 0.563 & 0.372 \\
Gender & 0.016 & -0.217 & 0.238 & 0.863 \\
Singleton - twin & 0.134 & -0.109 & 0.362 & 0.317 \\
Gestational age & 0.188 & -0.334 & 0.688 & 0.479 \\
High-risk pregnancy & -0.026 & -0.285 & 0.174 & 0.695 \\
$R^{2}$ & 0.203 & 0.116 & 0.535 & 0.002 \\
\hline
\end{tabular}

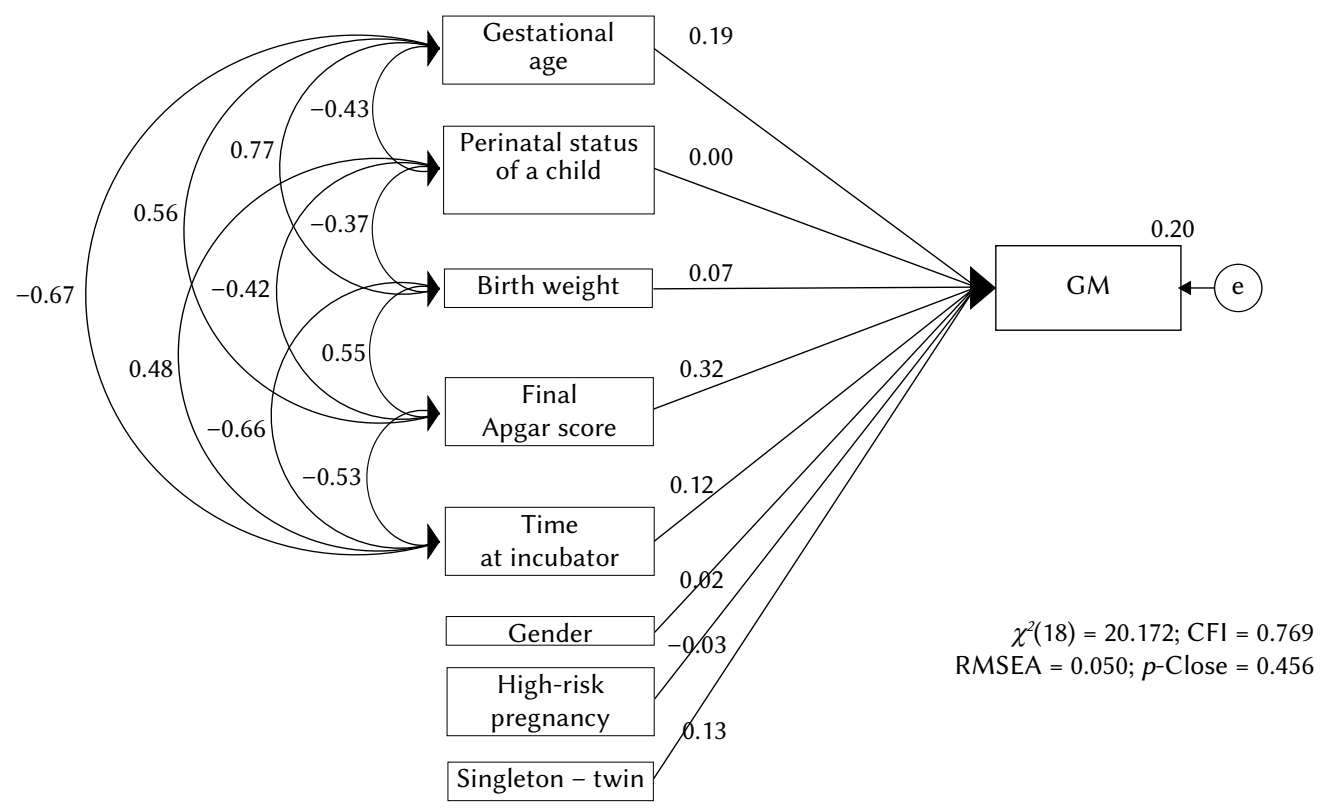

Figure 11. Model illustrating the influence of biomedical predictors on the GM scores.

the influence of gestational age on the psychomotor development of preterm infants.

Also birth weight constitutes a prognostic factor of the psychomotor development of preterm children during infancy and the peri-kindergarten period (Stoelhorst et al., 2003), and determines their intellectual and motor development (e.g. Dezoete, MacArthur \& Tuck, 2003), and IQ at older age (Bhutta et al., 2002, after: Sondaar et al., 2008). Many previous studies have dealt with the development of children with VLBW (e.g. Lan-Wang, Shan-Tair \& Chao-Ching, 2008; Addison et al., 2009; Datar \& Jacknowitz, 2009), or ELBW (e.g. Hack et al., 2000; Anderson et al., 2010; Kilbride, Thorstad \& Daily, 2004; Laptook, O’Shea, Shankaran \& Bhaskar, 2005; Gidley Larson et al., 2011). About $50 \%$ of children with VLBW show at least one deficit related to cognitive and motor spheres (Kmita, 2003). A study of 25 preterm babies born with ELBW (<801 g) and 25 full-term children with normal birth weight, examined at 3 and 5 years of age, revealed that their motor development was determined by the term of birth and the presence of prematurity-associated complications, while the development of cognitive and language functions was also modulated by the socioeconomic status of their families (Kilbride et al., 2004). Also our study confirmed this relationship, showing that higher birth weight is associated with a higher level of fine motor skills of preterm children, as well as with better cognitive functioning during early childhood.
Psychomotor development of preterm babies 
Table 10

Relationship between birth weight and MDI score $<70$ points at 20 months of corrected age (based on Hack et al., 2000)

\begin{tabular}{cccccc}
\hline & $\begin{array}{c}500-599 \mathrm{~g} \\
(n=12)\end{array}$ & $\begin{array}{c}600-699 \mathrm{~g} \\
(n=31)\end{array}$ & $\begin{array}{c}700-799 \mathrm{~g} \\
(n=52)\end{array}$ & $\begin{array}{c}800-899 \mathrm{~g} \\
(n=57)\end{array}$ & $\begin{array}{c}900-999 \mathrm{~g} \\
(n=68)\end{array}$ \\
\hline $\begin{array}{c}\text { MDI }<70 \\
\begin{array}{c}\text { Neurological } \\
\text { disorders }\end{array}\end{array}$ & $67 \%$ & $45 \%$ & $42 \%$ & $35 \%$ & $41 \%$ \\
\hline
\end{tabular}

Mariola Bidzan, Łucja Bieleninik

Table 11

Relationship between gestational age and MDI score < 70 points at 20 months of corrected age (based on Hack et al., 2000)

\begin{tabular}{ccccccc}
\hline & $\begin{array}{c}23^{\text {rd }} \text { week } \\
(n=8)\end{array}$ & $\begin{array}{c}24^{\text {th }} \text { week } \\
(n=21)\end{array}$ & $\begin{array}{c}25^{\text {th }} \text { week } \\
(n=42)\end{array}$ & $\begin{array}{c}26^{\text {th }} \text { week } \\
(n=55)\end{array}$ & $\begin{array}{c}27^{\text {th }} \text { week } \\
(n=43)\end{array}$ & $\begin{array}{c}28^{\text {th }} \text { week } \\
(n=24)\end{array}$ \\
\hline $\begin{array}{c}\text { MDI }<70 \\
\text { Neurological } \\
\text { disorders }\end{array}$ & $38 \%$ & $48 \%$ & $45 \%$ & $53 \%$ & $42 \%$ & $17 \%$ \\
\hline
\end{tabular}

When analyzing the influence of perinatal variables on the psychomotor development of a child, one cannot forget about the combined effects of birth weight and gestational age. Many previous studies revealed that gestational age below 32 weeks and birth weight corresponding to VLBW modulate the risk of neurological disorders, and especially cerebral palsy and mental impairment (van Kessel-Feddema et al., 2007). Preterm newborns with birth weight in the range $501-1000 \mathrm{~g}$, born before the $25^{\text {th }}$ week of gestation, represent a risk group of developmental delay (Hintz et al., 2005; Laptook et al., 2005; Anderson et al., 2010). The relationship between birth weight or gestational age and Mental Development Index (MDI) scores determined with BSID is presented in Tables 10 and 11, respectively.

Also according to Addison et al. (2009), birth weight corresponding to VLBW is associated with MDI and Psychomotor Development Index (PDI) scores below 70 points. We observed a significant association $(p<0.01)$ between MDI score below 70 points, gestational age of 25 weeks (range 23-29 weeks) and mean birth weight of $550 \mathrm{~g}$ (range 406-1439 g).

Postnatal status determines survival and further development of a child. Factors that can potentially cause developmental delay include clinical conditions resulting from preterm birth, such as bronchopulmonary dysplasia (Stoelhorst et al., 2003; van Kessel-Feddema et al., 2007), administration of corticosteroids, and low Apgar and SGA scores (van Kessel-Feddema et al., 2007). Our statistical analysis confirmed a significant association between Apgar score and motor development of preterm infants, with regards to both fine and gross motor skills. Previous studies showed that children with a history of peri- natal hypoxia may show abnormalities of psychomotor development also at older ages, corresponding to complete development of the brain (about 7-8 years of age) (Bałanda-Bałdyga et al., 2009); spastic upper limb hemiplegia and impairment of mental development can be observed in such cases (Kornacka, 2000). Although severe cerebral injuries have long-term consequences for linguistic development, a preterm baby raised in a family characterized by high status will more likely develop normal language skills (Luu et al., 2009); this fact emphasizes the compensatory abilities of parents.

Perinatal parameters constitute another predictor of future development. Although we did not verify the role of these factors, their effect has been confirmed by several other authors. A Dutch study (Rijken, Wit, le Cessie \& Veen, 2007) of 160 babies born before gestational week 32 ( $82 \%$ of survivors from the whole population) revealed that irrespective of child's gender, body height and weight and BMI determined at the age of two years were below reference values defined by the Dutch growth charts. Also intrauterine growth restriction affected all anthropometric parameters determined in preterm children at the age of two years. Although most preterm newborns have birth weight adequate for their gestational age, some of them are too small (body length below the $10^{\text {th }}$ percentile). Such children should be analyzed as a separate category since they are at risk of various prematurity-related complications (Mulder et al., 2009). Delayed growth (manifested by too low body length and/or weight) is also associated with abnormal neurological findings, smaller circumference of the head, and mental and psychomotor delay. Moreover, some authors have concluded that neurological 
development can be determined by head circumference (Rijken et al., 2007). According to most researchers, both body height and body weight of pretermborn children are smaller, especially in neonates with low birth weight; nevertheless, growth acceleration is reported in some children, most commonly during the first year of life. The intrauterine environment (location of fetus, availability of nutrients and maternal antibodies) and conditions during the perinatal period (such as hypoxia and ischemia) can be reflected by differences in the anthropometric parameters of monozygotic twins, evident since the early minutes of their postnatal life (Rostowski, 2010). A longitudinal twin study conducted by Gomółka-Walaszek and Walaszek (2008) showed that perinatal characteristics, i.e. gestational age, birth weight, sequence of delivery, and time between delivering the first and the second twin, modulate postnatal development and psychophysical conditions of infants. However, it is important from a psychological viewpoint that these differences can be neutralized by proper stimulation and "caregiver resources" (Gomółka-Walaszek \& Walaszek, 2008). The study by Yudin et al. (2001, after: Gomółka-Walaszek \& Walaszek, 2008), including a group of 364 babies with birth weight $<1250 \mathrm{~g}$, did not confirm the influence of factors related to multiple delivery (including birth weight, maturity, periventricular and intraventricular bleeding, chronic pulmonary conditions, or the socioeconomic status of parents) on cognitive development.

\section{CONCLUSIONS}

The conducted data analysis indicates that the subjective assessment of sexual life is related to the assessment of marital relation on the scale of emotional expression and relation coherence. No relation between sexual activity and sexual life with the assessment of the quality of marital relation was proved. However, the assessment of sexual life is related significantly to the assessment of the quality of marital relation.

\section{References}

Addison, K., Griffin, M., Moorman, J., Lake, D. \& O'Shea, T. (2009). Heart rate characteristics and neurodevelopmental outcome in very low birth weight infants. Journal of Perinatology, 29, 750-756.

Anderson, P.J., de Luca, C.R., Hutchinson, E., Roberts, G. \& Doyle, L.W., and the Victorian Infant Collaborative Group (2010). Underestimation of Developmental Delay by the New Bayley-III Scale. Archives of Pediatrics \& Adolescent Medicine, 164, 352-356.

Bałanda-Bałdyga, A., Skurzak, A., Iwanowicz-Palus, G.J., Bień, A.M. \& Kiełbratowska, B. (2009). Opieka nad wcześniakiem z wybranymi problemami klinicznymi. In: A.B. Pilewska-Kozak (ed.). Opieka nad wcześniakiem [Care for premature] (pp. 141-163). Warszawa: PZWL.

Bidzan, M. \& Bieleninik, Ł. (2013). Conditions of the Quality of Life and Life Satisfaction of Mothers of Preterm Babies in Poland. Journal of Socialomics, 2, e117.

Bidzan, M., Bieleninik, Ł. \& Lipowska, M. (2013). The development of speach in early childhood in children from twin pregnancies with twin-twin transfusion syndrome (TTTS). Polish Psychological Bulletin, 44, 9-20.

Bieleninik, Ł. (2012). Dzieci przedwcześnie urodzone w percepcji matek [Mothers' perception of prematurely born children]. Gdańsk: Wyd. Harmonia Universalis.

Bracewell, M. \& Marlow, N. (2002). Patterns of Motor Disability in Very Preterm Children. Mental Retardation and Developmental Disabilites Rerearch Reviews, 8, 241-248.

Czajka, R. (2010). Poród przedwczesny. In: G.H. Bręborowicz (ed.). Ciąża wysokiego ryzyka [High-risk pregnancy] (pp. 137-143). Poznań: MMX.

Datar, A., Jacknowitz, A. (2009). Birth Weigh Effects on Children's Mental, Motor, and Physical Development: Evidence from Twins Data. Matern Child Health J, 13, 780-794.

Dezoete, J.A., MacArthur, B.A. \& Tuck, B. (2003). Prediction of Bayley and Stanford-Binet scores with a group of very low birth weight children. Child: Care, Health \& Development, 29, 367-372.

Field, D.J., Dorling, J.S., Manktelow, B.N. \& Draper, E.S. (2008). Survival of extremely premature babies in a geographically defined population: prospective cohort study of 1994-9 compared with 2000-5. British Medical Journal, 336, 1221-1223.

Gidley Larson, J.C., Baron, I.S., Erickson, K., Ahronivich, M.D., Baker, R. \& Litman, F.R. (2011). Neuromotor Outcomes at School Age After Extremely Low Birth Weight: Early Detection of Subtle Sings. Neuropsychology, 23, 66-73.

Gomółka-Walaszek, I. \& Walaszek, A. (2008). Interakcje opiekowania się w rozwoju psychoruchowym bliźniąt. Perinatologia, Neonatologia i Ginekologia, 1, 294-301.

Gotsh, F., Romero, R., Erez, O., Vaisbuch, E., Kusanovic, J.P., Mazaki-Tovi, S., Kimi, S.K., Hassan, S. \& Yeo, L. (2009). The preterm parturition syndrome and its implications for understanding the biology, risk assessment, diagnosis, treatment and prevention of preterm birth. The Journal of Maternal-Fetal and Neonatal Medicine, 22, S2, 5-23.

Hack, M., Wilson-Costello, D., Friedman, H., Taylor, G.H., Schluchter, M. \& Fanaroff, A.A. (2000). Neurodevelopment and Predicators of Outcomes of Children With Birth Weights of Less Than $1000 \mathrm{~g}$.
Psychomotor development of preterm babies 
Archives of Pediatrics \& Adolescent Medicine, 154, 725-731.

Hemgren, E. \& Persson, K. (2004). Quality of motor performance in preterm and full-term 3-year-old children. Child: Care, Health \& Development, 30, 515-527.

Hemgren, E. \& Persson, K. (2006). Associations of motor coordination and attention with motor-perceptual development in 3-year-old preterm and full-term children who needed neonatal intensive care. Child: Care, Health \& Development, 33, 11-21.

Mariola Bidzan, Łucja Bieleninik

Hintz, S.R., Kendrick, D.E., Vohr, B.R., Poole, W.K. \& Higgins, R.D. (2005). Changes in Neurodevelopmental Outcomes at 18 to 22 Months' Corrected Age Among Infants of Less Than 25 Weeks' Gestional Age Born in 1993-1999. Pediatrics, 115, 1644-1651.

Kiechl-Kohlendorfer, U., Ralser, E., Pupp Peglow, U., Reiter, G. \& Trawöger, R. (2009). Adverse neurodevelopmental outcome in preterm infants: risk factor profiles for different gestational ages. Acta Pediatrica, 98, 792-796.

Kilbride, H.W., Thorstad, K. \& Daily, D.K. (2004). Preschool Outcome of Less Than 801-Gram Preterm Infants Compared With Full-Term Siblings. Pediatrics, 113, 742-747.

Kmita, G. (2003). Rozwój psychiczny dzieci urodzonych przedwcześnie. In: M.K. Kornacka (ed.). Noworodek przedwcześnie urodzony - pierwsze lata życia [Preterm newborn: first years of life] (pp. 55-67). Warszawa: PZWL.

Kornacka, M.K. (2000): Zaburzenia neurologiczne. In: J. Szczapa (ed.). Neonatologia [Neonatology] (pp. 533-565). Warszawa: PZWL.

Kornacka, M.K. (2003). Rozwój dzieci z ciąż wielopłodowych. In: G.H. Bręborowicz, W. Malinowski, E. Ronin-Walknowska (eds.). Ciazza wieloptodowa [Multiple pregnancy] (pp. 363-371). Poznań: OWN.

Kostuch, M. (2009). Noworodek urodzony przedwcześnie - odrębności anatomiczne i fizjologiczne. In: A.B. Pilewska-Kozak (ed.). Opieka nad wcześniakiem [Care of Premature] (pp. 44-60). Warszawa: PZWL.

Lan-Wang, W., Shan-Tair, W. \& Chao-Ching, H. (2008). Preterm infants of educated mothers have better outcome. Acta Pediatrica, 97, 568-573.

Laptook, A.R., O'Shea, M., Shankaran, S. \& Bhaskar, B. (2005). Adverse Neurodevelopmental Outcomes Among Extremely Low Birth Infants With a Normal Head Ultrasound: Prevalence and Antecedents. Pediatrics, 115, 673-680.

Luu, T.M., Vohr, B.R., Schneider, K.C., Katz, K.H., Tucker, R., Allan, W.C. \& Ment, L.R. (2009). Trajectories of Receptive Language Development from 3 to 12 Years in Very Preterm Children. Pediatrics, 124, 333-341.

Maguire, C.M., Walther, F.J., van Zwieten, P.H.T., Le Cessie, S., Wit, J.M. \& Veen, S., behalf of the Leiden Developmental Care Project (2009). Follow-up Outcomes at 1 and 2 Years of Infants Born Less Than
32 Weeks After Newborn Induvidualized Developmental Care and Assessment Program. Pediatrics, 123, 1081-1087.

Marlow, N., Wolke, D., Bracewell, M.A. \& Samara, M. (2005). Neurologic and developmental disability at six years of age after extremely preterm birth. The New England Journal of Medicine, 352, 9-19.

Martens, S.E., Rijken, M., Stoelhorst, G.M., van Zwieten, P.H., Zwinderman, A.H., Wit, J.M., HaddersAlgra, M. \& Veen, S. (2003). Is hypotension a major risk factor for neurological morbidity at term age in very preterm infants? Early Human Development, 75, 79-89.

Morris, B.H., Smith, K.S., Swank, P.R., Denson, S.E. \& Landry, S.H. (2002). Patterns of Physical an Neurologic Development in Preterm Children. Journal of Perinatology, 22, 31-36.

Mulder, H., Pitchford, N.J., Hagger, M.S. \& Marlow, N. (2009). Development of Executive Functions and attention in Preterm Children: A Systematic Review. Developmental Neuropsychology, 34, 393-421.

Ragusa, G. (2009). Born too soon: what can we expect? Nature of home literacy experiences for children with very low birth weight. Early Child Development and Care, 179, 651-670.

Rijken, M., Stoelhorst, G., Martens, E., van Zwieten, P.H., Brand, R., Wit, J.M. \& Veen, S. (2003). Mortality and neurologic, mental and psychomotor development at 2 years in infants born less than 27 weeks' gestation: the Leiden Follow-Up Project on Prematurity. Pediatrics, 112, 351-358.

Rijken, M., Wit, J.M., le Cessie, S. \& Veen, S. (2007). The effect of perinatal risk factors on growth in very preterm infants at 2 years of age: the Leiden Follow-up Project on Prematurity. Early Human Development, 83, 527-534.

Rostowski, J. (2010). Bioneuropsychologiczne aspekty rozwoju bliźniąt. In: T. Rostowska, B. Pastwa-Wojciechowska (eds.). Rozwój bliźniąt w ciagu życia. Aspekty biopsychologiczne [The Development of Twins over a Lifetime. Biopsychological Aspects] (pp. 11-39). Kraków: Oficyna Wydawnicza „Impuls”. Saigal, S., den Ouden, A.L., Wolke, D., Hoult, L., Paneth, N., Streiner, D.L., Whitaker, A. \& Pinto-Martin, J. (2003). School-age outcomes in children who were extremely low birth weight from four international population-based cohorts. Pediatrics, 112, 943-950.

Sondaar, M., van Kessel, B.J.M., de Kleine, M.J.K., Briët, J.M., den Ouden, A.L. \& van Baar, A. (2008). Do Pediatricians Recognize Cognitive Developmental Problems in Preterm Children at Age 5 Years? Journal of Developmental and Physical Disabilities, 20, 21-29.

Stoelhorst, G.M.S.J., Rijken, M., Martens, S.E., van Zwieten, P.H.T., Feenstra, J., Zwinderman, A.H., Wit, J.M. \& Veen, S. (2003). Developmental outcome at 18 and 24 months of age in very preterm children: 
a cohort study from 1996 to 1997. Early Human Development, 72, 83-95.

van Kessel-Feddema, B., Sondaar, M., de Kleine, M., Verhaak, C. \& van Baar, A. (2007). Concordance between school outcomes and developmental follow-up results of very preterm and/or low birth weight children at the age of 5 years. European Journal of Pediatrics, 166, 693-699.

Wechsler Linden, D., Paroli, E.T. \& Doron, M.W. (2007). Wcześniak. Pierwsze 6 lat życia [Premature. The First Six Years of Life]. E. Helwich (ed.). Warszawa: PZWL.

Wielenga, J.M., Smit, B.J., Merkus, M.P., Wolf, M.J., van Sonderen, L. \& Kok, J.H. (2009). Development and growth in very preterm infants in relation to NIDCAP in a Dutch NICU: two years of follow-up. Acta Paediatrica, 98, 291-297.

Wood, N.S., Costeloe, K., Gibson, A.T., Hennessy, E.M., Marlow, N. \& Wilkinson, A.R., EPICure Study Group (2005). The EPICure study: associations and antecedents of neurological and developmental disability at 30 months of age following extremely preterm birth. Archives of Disease in Childhood-Fetal and Neonatal, 90, 134-140.

Woodward, L.J., Anderson, P.J., Austin, N.C., Howard, K. \& Inder, T.E. (2006). Neonatal MRI to Predict Neurodevelopmental Outcomes in Preterm Infants. The New England Journal of Medicine, 355, 685-694. 